\title{
Article
}

\section{The fabrication of memory in communication}

\author{
Fell, Elena Vladimirovna
}

Available at http://clok.uclan.ac.uk/7441/

Fell, Elena Vladimirovna (2011) The fabrication of memory in communication. Empedocles European Journal for the Philosophy of Communication, 2 (2). pp. 227-240. ISSN 1757-1952

It is advisable to refer to the publisher's version if you intend to cite from the work. http://dx.doi.org/10.1386/ejpc.2.2.227_1

For more information about UCLan's research in this area go to http://www.uclan.ac.uk/researchgroups/ and search for < name of research Group>.

For information about Research generally at UCLan please go to http://www.uclan.ac.uk/research/

All outputs in CLoK are protected by Intellectual Property Rights law, including Copyright law. Copyright, IPR and Moral Rights for the works on this site are retained by the individual authors and/or other copyright owners. Terms and conditions for use of this material are defined in the policies page.

\section{CLoK}

Central Lancashire online Knowledge www.clok.uclan.ac.uk

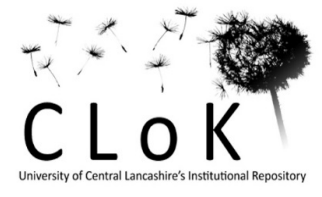




\section{The fabrication of memory in communication.}

\section{Psychological research on memory alteration}

When we think of the relation between memory and communication, some things seem straightforward. Our memories, accumulated over a period of time are fed into our conversations and dialogues, sometimes giving us factual data that we recall, sometimes endowing us with rhetorical and performance skills that we acquired previously and which we are now putting in practice. Speaking in temporal terms, our memories precede our communications, and the processes of memorizing, recalling and implementing the recalled material correspond to the unidirectional sequential flow from the past to the present. Whilst present situations can be marked by a degree of uncertainty (no one knows whether a current conversation, interview or an exam is a successful event before it has actually finished), past events have already taken place and gained their final and definite forms. The content of past occurrences is set and unchangeable and, accessed via memory, serves us as a reliable foundation for our current and future communications. There is no reason for us not to rely on our memories of the past: even though some memories may fade and some may be completely forgotten, what we do remember is good enough to underpin what we do and say in our present, provided we remain in a sound state of mind.

Psychological research undermines this comforting view of our memory. 'Human memory is subject to a multitude of errors', Arndt says. ${ }^{1}$ To name but a few, Zaragoza and Lane write about errors associated with source misattributions ${ }^{2}$; Schacter investigates memory distortions ${ }^{3}$ and Loftus, ${ }^{4}$ Roedger $\&$ McDermott research the creation of false memories. ${ }^{5}$ In particular, psychologists and communication theorists challenge our simplistic belief in a linear development where memorizing something precedes an act of

${ }^{1}$ Arndt, J. (2010). The Role of Memory Activation in Creating False Memories of encoding Context. Journal of Experimental Psychology; Learning, Memory and Cognition, Vol. 36 Issue 1, p. 66. check citation

${ }^{2}$ Zaragoza, M. S., \& Lane, S. M. (1994). Source misattributions and the suggestibility of eyewitness memory. Journal of Experimental Psychology; Learning, Memory and Cognition, 20, 934 - 945.

${ }^{3}$ Schacter, D. 1. (1995). Memory distortions: How minds, brains, and societies reconstruct the past. Cambridge, MA: Harvard University Press.

${ }^{4}$ Loftus, E. F. (1993). The reality of repressed memories. American Psychologist, 48, 518 - 537.

${ }^{5}$ Roediger, H. L., III, \& McDermott, K. B. (1995). Creating false memories: Remembering words not presented in lists. Journal of Experimental Psychology; Learning, Memory and Cognition, 21, 803 - 814. 
communication and where recalling something aids communication. They note the opposite current as well: not just the past memory precedes and aids consequent communications but consequent communication situations also have an effect on our memories.

Remembering is affected by motivation, King observes. ${ }^{6}$ Remembering is selective, and we tend to remember what we need or want. Motivation can both increase and reduce remembering, and this in itself indicates that communication plays a significant role in remembering inasmuch as a concrete communication situation may motivate us to remember something or repress the memory of it. More significantly, psychologists recognize that rather than being reproductive, memory is reconstructive in nature and, as King notes, items that we retrieve from memory are rarely the same as the items initially perceived, or acquired. ' $F a r$ from being an infallible guide to the replication of a past event, it [recollection] is actually a means of recreating - or perhaps even creating it in the other events in memory storage. ${ }^{8}$

King points out that the modification of memorized material is due to the need to align it with our past experience. This implies that while the process of memorizing takes place we already amend the perceived reality in our mind, store and retrieve information which does not reliably reflect what we have actaully experienced. ${ }^{9}$ Todorov in his article 'Communication effects on memory and judgment ${ }^{\text {' }}{ }^{10}$ provides evidence that the creating of memories indeed takes place but he also demonstrates that the alteration and creation of memories happen retrospectively, under the influence of later communicative situations.

Having researched specifically memory correction in communication situations, Todorov (New York University, USA) describes the following experiment in detail. Forty-eight students were asked to read an essay about another student, Donald. The essay contained seven statements about him, written in such a way that readers could interpret them in positive or negative terms with equal likelihood. The ambiguity of those statements was a key factor in the experiment as it enabled the experimenters to see which factors would sway the participants in the direction of positive or negative judgment about Donald, and later test

\footnotetext{
${ }^{6}$ King, Corwin P. 'A Functional Model of Memory in Communication', Paper presented at the Annual Meeting of the International Communication Association (New Orleans, April 17 - 20, 1974), p. 7

${ }^{7}$ King, p. 7

${ }^{8}$ King, p. 8

${ }^{9}$ King, p. 7

${ }^{10}$ Todorov, A. 'Communication effects on memory and judgment', European Journal of Social Psychology, 32, (2002), pp. 531 - 546.
} 
their memory of those judgments. After reading the essay eleven participants had to rate Donald on eight 7-point scales constructed around positive and negative trait interpretations of the ambiguous stimulus information. For example, one of the statements was: 'A lot of people enjoy Donald's humour. He is in the habit of making jokes out of the blue. Often times at parties his humour is quick to address the faults that people have or the mistakes that they have made. ${ }^{11}$ Having read this about a person, one could say that he or she is witty, if they are swayed towards making a positive judgment, or that the person in question is sarcastic, if a negative response seems more appropriate. The same applied to other descriptions of Donald's character. Depending on the participants' attitude, he could be rated as persistent or stubborn; cultivated or artificial; self-confident or conceited; thrifty or stingy; independent or aloof; adventurous or reckless.

In addition to the essay, participants were also presented with the pairs of words, some of which had been mentioned in the essay and some had not. These were daring/reckless, self-confident/self-important, cultivated/snobbish, thrifty/tightfisted, amusing/sarcastic, persistent/stubborn, independent/aloof. Also, the test included additional seven positive and seven negative traits which were not applicable to the original descriptions. The positive ones were tolerant, trustworthy, easygoing, relaxed, inventive, cooperative, and warm. The negative ones were ungrateful, disagreeable, irresponsible, envious, abusive, unadjusted and dishonest. All above information was randomized, and trait words were mixed with an extra provision of non-trait words.

Although the study was aimed at evaluating the influence of communication situation on judgment and memory correction, the participants were told that the purpose of the experiment was to research interpersonal perception and communication. As they arrived, they met yet another student who supposedly had taken part in the same study last year, and were told that they would be reading a text about someone from that student's group. As they started reading the essay about Donald, they thought that their ultimate task was to describe Donald in such a way so that the last year participant that they had just met would recognize Donald from their descriptions. They also thought that the addressee of their report on Donald had met Donald in person and had an opportunity to witness the full spectrum of Donald's behavioral traits.

${ }^{11}$ Todorov, p. 536 
The highlight of the experiment consisted in the fact that the experimenter casually mentioned to the quarter of the participating group that the addressee seemed to like Donald, and another quarter were told in an equal off-hand manner that the addressee seemed to dislike Donald. This was done in order to introduce a subtle presentation of addressee attitude. The rest of the group were also divided in half and told blatantly of the addressee attitude. The experimenter told the third quarter of students that the addressee liked Donald and if they described Donald in positive terms it would help the addressee recognize him. On the other hand the remainder of the students were told that the addressee disliked the target person and recognition would be made easier if they described Donald negatively. These participants were specifically asked to take the addressee's attitude into account whilst producing descriptions of Donald. After reading the essay the students wrote Donald's profile without naming him, believing that only the addressee would be reading this. Two days later participants were summoned again and presented with the judgment, recall and recognition tasks. They had to rate how much they liked Donald themselves and were asked to rate to what degree their descriptions of Donald were affected by the addressee's attitude.

"On both memory measures, evaluative extremity of recall and false recognition of traits, participants were influenced in the direction of the addressee's attitude," Todorov summarizes the results of the experiment ${ }^{12}$. Participants who were told that the addressee liked Donald described him more positively and participants who were told that the addressee disliked him described Donald more negatively. This effect was stronger in the group where the addressee's attitude was presented subtly, although those participants in particular did not believe that their descriptions were significantly affected by the addressee's attitude. Their opinions were swayed without them realizing it! Moreover they were more likely to falsely recognize either positive or negative traits which had not been mentioned in the original essay according to the way in which their opinions were directed. Those whose attention was deliberately drawn to the addressee's attitude were affected to a lesser degree because, conscious of the possibility of such influence, they were able to put up some resistance to it. Their judgments of Donald were not affected but, remarkably, the results of their memory tasks showed that they could not resist the influence then.

When communication bias was not apparent to the participants, they relied on their own descriptions of Donald to make a judgment or to retrieve the original information. When the participants were aware of

\footnotetext{
${ }^{12}$ Todorov, p. 540
} 
the bias, they relied on their descriptions too, but they were conscious of the fact that the addressee's attitude could have a mind manipulating effect on their judgments, so they attempted to avoid this influence. This happened when the addressee's attitude was presented blatantly. Nevertheless the attempts to bypass the influence were not successful in escaping from evaluative biases in memory. 'The recognition findings clearly showed communication effects on memory independent of the presentation of the addressee's attitude.' ${ }^{13}$ When the bias was introduced subtly, both judgments and memory were swayed towards it but, when participants were openly exposed to a bias, they were able to correct their judgments but could not correct their memory sufficiently. 'Memory was reliably affected by the act of communication'. ${ }^{14}$

Todorov includes the following statement in his concluding remarks. What people say or how they describe a person is influenced by a variety of features of a specific communication situation. Situationally induced shifts in communication can have an effect on one's cognition. We can correct for unwanted communication influences on judgments when we are aware of the bias, but may not be able to correct for effects on memory. ${ }^{15}$

Todorov's account is not the only piece of scientific evidence demonstrating that our memories change retrospectively under the influence of concrete communication situations. Psychologists engage in extensive research in memory alteration, creation of false memories, false recognition etc. Their reports provide accounts of situations where people were made to recall events that had never happened to them or mistakenly recognise items that they thought they had seen in a list of words previously. Psychologists' reports contain accounts of situations with a very restricted content such as remembering, forgetting or recognising isolated words, statements or images. Scientific data here are collected in a controlled environment, where experimenters analyse artificially isolated instances of information processing. This, however, should not mean that memory alterations are limited to such instances. In fact, it would be reasonable to suggest that psychologists' findings provide an insight into how our memory functions in general, and that their experiments expose a tendency in our thinking that is spread wider than we would like to admit to ourselves.

\footnotetext{
13 Todorov, p. 543.

${ }^{14}$ Todorov, p. 544

${ }^{15}$ Todorov, p. 544
} 
It is very likely that the results of Todorov's experiment relate not just to a limited number of communicative situations, when people discuss someone else, gossip, give and receive references. On the contrary, Todorov's experiment reveals a more serious situation that concerns the very nature of our selfhood. The experiment proves that our memories can be altered by an outside bias in principle, and this would include the memories of ourselves, of our own past, and our judgements about it.

As we grow up, mature and grow old, society changes and so does the bias that it provides, and we may have to admit that we constantly recreate our own past, adjusting it to the current system of societal values and beliefs. This would also mean that our memory may not be able to access the authentic view of our self as it was, say, ten years ago, because we have been constantly creating new images of that period making them fit into our current communicative situations.

Scrutinizing the causes of memory alterations, researchers look for psychological, somatic, and social reasons. There are claims that activities that engage participants in the process of imagining details of a false event can make them remember the false event as if it happened for real. For example, Hyman \& Pentland ${ }^{16}$ found that participating in guided imagery can influence the development of false memories. Porter, Birt, Yuille, \& Lehman ${ }^{17}$ assert that pairing an introverted participant and an extroverted interviewer can lead to memory distortion. Mitchell \& Johnson ${ }^{18}$ explain that activities that encourage imagination also promote false memories. According to them, when we recall a memory we decide for ourselves that is a memory of a real event if we can trace it back to its source, i. e. whether we really did something or merely imagine having done it. We can however, make a source-monitoring error, because we do not store memories with information about their source as when a memory is activated it is accompanied by a feeling of familiarity, or a sense of reliving the emotional or perceptual details of the original event.

\section{Ontological and existential causes of the fabrication of memories}

\footnotetext{
${ }^{16}$ Hyman, I. E., \& Pentland, J. (1996). The role of mental imagery in the creation of false childhood memories. Journal of Memory and Language, 35, $101-117$.

${ }^{17}$ Porter, S., Birt, A. R., Yuille, J. C., \& Lehman, D. R. (2000). Negotiating false memories: Interviewer rememberer characteristics relate to memory distortion. Psychological Science, 11, $507-510$.

${ }^{18}$ Mitchell, K. J., \& Johnson, M. K. (2000). Source monitoring: Attributing mental experiences. In E. tulving \& F. I. M. Craik (Eds.), The Oxford handbook of memory (pp. 179-195). New York: Oxford University Press.
} 
An investigation into the psychological causes of memory alteration gives us a sense that the fabrication of memories, although probably inevitable, is due to an imperfection of our mind. I would like to offer a philosophical analysis of memory fabrication addressing its deep ontological and existential causes. In the course of this analysis it will become apparent that the fabrication of memories is not due to some unfortunate malfunction of our brain but has its ontological backing in the very structure of communicative reality and in our existential striving to be part of this reality.

The conceptual understanding of our communications requires constant memory adjustment. When we hear a speech, or a sentence being pronounced, we constantly need to make retrospective amendments so as to understand the unique meaning of the whole piece that we have heard so far.

For example, when Thatcher's 'The lady's not for turning' speech was heard for the first time, the perception of the following passage may have involved the following stages (a simplified view, as the comprehension of each new word and even sound would have involved retrospective adjustments as well):

To those waiting with bated breath for that favourite media catchphrase, the "U" turn, I have only one thing to say. "You turn if you want to. The lady's not for turning." I say that not only to you but to our friends overseas and also to those who are not our friends. ${ }^{19}$

Stage 1. The audience has heard:

To those waiting with bated breath for that favourite media catchphrase, the "U" turn, I have only one thing to say.

This sentence, albeit with a captivating rhythm, is straightforward. It may have evoked interest but entailes no surprises.

Stage 2. The audience has heard:

19

Margaret Thatcher, Speech to Conservative Party Conference ('the lady's not for turning'), 1980 Oct 10, Thatcher Archive: CCOPR 735/80 
To those waiting with bated breath for that favourite media catchphrase, the "U" turn, I have only one thing to say. "You turn if you want to."

When the audience hears [ju:] in "You turn" they think that this is "U" in "U" turn" because both sound the same. When they hear the rest of the sentence they realize that it was, in fact, "You turn". They make a significant retrospective adjustment here. Overall the phrase "You turn if you want to" throws a negative light onto the previously mentioned phrase "U" turn", mocks it, portrays it as despicable cowardice.

Stage 3. The audience has heard:

To those waiting with bated breath for that favourite media catchphrase, the "U" turn, I have only one thing to say. "You turn if you want to. The lady's not for turning."

"The lady's not for turning" makes the previously mentioned "U" turn" and "You" utterly despicable and in unfavorable opposition to the speaker's fearless and stern attitude.

Stage 4. The audience has heard:

To those waiting with bated breath for that favourite media catchphrase, the "U" turn, I have only one thing to say. "You turn if you want to. The lady's not for turning." I say that not only to you but to our friends overseas and also to those who are not our friends.

The last sentence is straightforward and contains no conceptual challenges. This last sentence is there like a noisy pause which allows listeners time to wonder at what has already been said.

To take a biographical, example, Wellington's biographer, Richard Holmes, in his account of the Iron Duke's earlier years, mentions: “...[H]e was soundly thrashed by a young blacksmith named Hughes, who was proud to relate how he had beaten the man who beat Napoleon."20

Holmes brings this up as nothing more than an amusing anecdote, but it helps us observe the work of time that makes changes in the past. The youngster whom Hughes had thrashed was not, of course, the

${ }^{20}$ Richard Holmes, Wellington The Iron Duke, HarperCollins Publishers, 2002, p. 8 
Duke of Wellington who celebrated the victory at Waterloo. He was not even the future Duke of Wellington, because when the scuffle with the blacksmith took place somewhere in the 1780s, the future did not shape itself favourably for Arthur Wellesley. Far from expecting him to become a significant figure in the history of Europe, his family hoped that he would merely get by in life, so to speak, and a free commission in the army was not the preferred but the only option available to the sixteen year old of no special talents or fortune. Such were the present situation and the future projection of it for Arthur in the mid eighties.

Thirty years on, when the present time falls on the year 1815, Arthur Wellesley is Duke of Wellington and a national hero. We can see how the embodied eventuality of 1815 changes the nature of an event which happened back in the 1780s. By 1815, the Arthur Wellesley of the 1780s in 1815 had become the future Duke of Wellington who would beat Napoleon. So it is only retrospectively that Hughes the blacksmith became the one who had beaten the man who was to beat Napoleon, and not when the scuffle between the young men actually took place.

Now let us think of the numberless, sometimes imperceptible changes that happen in our lives as we progress from our first spoken words to our old age. Each time a new addition to our personal history takes place it throws its light, or its shadow backwards onto what we were before, including every stage of it. Depending on what we do later, our childhood retrospectively becomes a prelude to a dazzling career or to a dull, monotonous existence, and when we are old, our youth becomes a beginning of what we have become in our old age - a person rich in grandchildren and friends, or someone whose name will be swiftly forgotten when his or her life expires. But neither our childhood, not our youth are parts of that later history until that later history actually takes place!

If we agree that communicative reality changes retrospectively and if we look at memory as a faculty that assists us in accessing the past of communicative reality, then rigid, unyielding memory that sees events exactly as they were when they were first experienced, perceived and memorized, would not help us when we need to access the past that has changed and align it with the events that followed and with the new present. Remembering everything clearly and exactly would prevent us from adapting to new social demands for they may well contradict the social norms that we knew years ago. We would not be able to accept new technology because we would remember too well our lives when we lived without a feeling that 
we were missing out on something. For example, we may not be able to accept the idea of writing emails to our friends if we remember how nicely different it was to send and receive handwritten letters, the anticipation while waiting for that envelope, the satisfaction of leaving one's own trace on paper and the personal visual and tactile contact with the letter as object that the other person created, held and saw. In order to enjoy writing emails we must forget or deflate the pleasant side of writing by hand and instead our memory must create or inflate the sense of frustration and dissatisfaction that we may have felt when emails were not available, when messaging was inefficient and slow.

If we refuse to adjust our memories to the present social demands and to turn them into a foundation for the socially required new attitude, if we remain rigid and faithful to our past state of mind, we may create a discord between the past and the present. This would mean that the continuity between us past and us present may not be successfully formed and we may be confined to the trap of the past, hiding amongst our memories of past years or decades, frightened to embrace the present and missing out on new opportunities, new pleasures and new friendships. Time heals, they say, but it would not be able to heal our pains if we insisted on remaining faithful to our original memories and refused to change them. We would be unable to stop grieving over the dead and to forgive our loved ones, or connect with other people in the present. We would lose touch with reality in a full sense because whilst we are refusing to move on, the past that we are holding on to has itself moved on and has gained a different flavour in the light of what happened after it had gone.

According to my observations, people who lived through the collapse of the Soviet Union, had to face a complete change of values, and the process of adaptation seemed less traumatic for those who, (as far as I observed) fabricated or inflated their own supposed disagreement with the system prior to the political changes. Was that a betrayal of one's own former beliefs? Rather an adaptation to a new social reality as it changed in such a way that firstly, the former values gained negative connotations and secondly, there was no longer any framework within which upholding those values was meaningful. Many people who held on to Soviet communist ideas in their 1960s or 1970s versions seemed to have just fallen out of real time as they lost the platform on which they stood strong, full of utopian ideas and national pride.

To summarize, the relation of our past memories and our communication with others is not simply that of linear causality, whereby our memories smoothly glide into our communicative performance and 
remain unaffected themselves. Psychologists reveal the opposite process where a current communication has an effect on our memories, not just influencing their selection but also producing false recognition. The relationship of memory and communication is twofold, and effective social integration calls for the spontaneous fabrication of memories. The information that is communicated to us may contradict our previous beliefs, our previous understanding of the matter in question, and even threaten our established worldview. We are required to maintain the communicative process and respond to new demands, and so we have to find ways of adapting ourselves to the new information, even if our past experiences and beliefs cannot serve as a foundation for accepting it. We construct such foundation retrospectively, making ourselves believe that we were being prepared for this new situation by retrospectively created past attitudes and emotions. Our memory needs to be changeable in order for us to be able to catch up with the entirety of dynamic communicative reality which includes the past that itself has changed to fit in with the present.

\section{Epistemological implications of memory fabrication.}

What if we need to revisit the past is it was for research purposes or if we are conducting and investigation? Sometimes we need memorial accuracy for legal reasons, or as biographers or historians. Regrettably, the specific ontology of communicative reality prevents us from accessing past as it was. The problem in accessing past events in their pure form lies in the fact that our observation point in our actual temporal position interferes with our imaginary position in the remote past.

When discussing temporal continuity we often overlook the fact that such a discussion involves an observer - the one who imagines and discusses it, a biographer or historian, or even the same person that was involved in that past but who has become older and had new experiences since then. By treating the observer as an outsider we ignore the fact that both the observer and the researched events being observed belong to the same global temporal reality and thus ignore the observer's role and involvement in the process of observation.

The observer's position creates a certain perspective of what we observe, relative to our position, and affects the way we perceive things. As observers we are positioned in the real, actual present and, looking 
into the past, we adopt an imaginary position whereby we place ourselves at the outset of the process which we observe from the remote past to the more recent past or to the present moment.

By positioning ourselves in this way and following the order in which events happened, we gain a projection of reality from the past to the present. This seems to be a reliable way of accessing the order of real events in the past, but in actual fact, we do not follow this order. In our imagination, we abandon our real position in real present and place ourselves in the remote past, treating that past as the present observation point, but actually we still belong to our present, which is the ultimate point of global temporal reality which includes the unrolling reality that we observe and our own time as well. We end up with an overlap of two observation points: the point of our embodied existence in the actual present and the point in the remote past which we treat as the present.

Our attempts to follow the development of past reality in its pure form cannot succeed because our real position of a person who knows how the process unrolled cannot regain the innocence of the participant who, contemporaneous with the temporal process, is immersed in it and has the primary experience of the newness of what is happening and the uncertainty of what will happen next. When our point of view is split between the actual present and the remote present back in the past, both positions interfere with each other.

When we observe events whilst living them we have the original view of the original events. When we remain in our actual present, we do not know what the next temporal phase will be, so we do not focus on searching for the foundations of that next phase. The next phase has not happened yet so we do not know a foundation of exactly what events the current situation will be. When we look back, the next phase has taken place and retrospectively made the previous phase its own foundation. Thus we, accessing the past from the present, access the past that has been changed by the following events, not the original past. In the situation of the split position, the imaginary observer, thrown back in time, is informed by the actual observer in the present of the sequence of events which followed that remote position in time. Thus, if we agree to treat that imaginary position as present, the future of that present is fixed for the observer, something that real life observations do not entail. Indeed, when that past was present, its future was uncertain and unknown, therefore there could not have been a solid foundation for that future because it finalised itself only when it became present. 
As was discussed earlier, consequent events affect the nature of the preceding events, transforming them into the foundation for the following events. So when, as the present observer, in our imagination we position ourselves "at the back of time", we deal with the past which has been transformed by the following events, and not with the unscathed temporal reality which was unscathed only when it was present. As the observer of past events, we insist on treating the remote past as if it were both the unscathed present, unaffected by the future, and the past foundation of the following events, affected by those events which were future but have finalised themselves as present at some stage in the past. As follows from the previous discussion, when the present reality becomes past, it is not the same reality any more: it is altered by its relations with the subsequent events.

\section{3.b. Moral implications of memory fabrication}

The talk of the changeability of our memories, including the memories that we have of ourselves leads us to the issue of the changeability of our identity over time. Questions about the temporal instability of human identity were raised before. For example, Derek Parfit investigated the theme of the changeability of personhood in connection with moral principles and questions of justice. He talks of a situation where a person commits a crime at time $t$. When he (or she) is caught at a much later time $t^{\prime}$ he (or she) may be a different person, a person with a different character, a 'later self' of the person who committed the crime, not fully identical to the person who had committed the crime. Parfit questions whether the punishment is deserved in such cases. ${ }^{21}$ The idea that is being put forward by Parfit is not that the punishment is not deserved, but that the situation is complicated, as the changeability of a person over time creates ambiguities and questions.

Whilst revealing the complexity of the issue of changing identity, Parfit only talks about the linear changeability of identity where our character imperceptibly but significantly changes over time in such a way that if we consider our younger self and our older self separated by, say, ten years, there would be a week psychological connectedness between the younger 'I' and the older ' $I$ '. this in itself has challenging

${ }^{21}$ Derek Parfit, "Later Selves and Moral Principles" in: A. Montefiore, Philosophy and Personal Relations (ed.) Routledge \& Kegan Paul, London, 1973

Also: Derek Parfit, Reasons and Persons, Clarendon Press, Oxford, 1991 
consequences for our relationships. The implications of supposed linear changeability are hard enough. For example, the awareness of this makes it difficult for people when they wait for someone who is due to reappear after years of separation, say, after a prison sentence, as they rightly fear that the former person may have gone for good.

Our discussion, following Todorov's experiment, adds another dimension to the question of the changeability of selfhood. Not only people change continuously in the direction from the past to the future, but they also change retrospectively, aligning the knowledge of their past self with their current values and beliefs, the successful alignment contributing to their social adaptation at the present moment. But whilst the fabrication of memories may facilitate our communications and social integration, what does it do to our selfhood? Do we betray our former self by renouncing our past in favour of the practical gain of effective communication or does this change contribute to our personal growth? To what extent is the present self committed to the promises made by the earlier self? The complexity of this problem cannot be overestimated.

There are both ontological and existential reasons why the fabrication of memories is not a frustrating flaw of the work of our consciousness but a necessary mechanism of adaptation to reality that changes in its entirety all the time and includes retrospective additions to the past. But if we accept the normality of memory fabrication, we legitimise the constant changeability of one's own entire person inasmuch as one's personhood is largely founded on one's perceptions of one's own past self. We act now according to the rules that we learnt when we were young. We pay mortgage instalments now because we took on this commitment when we were fifteen years younger, and look after an old animal now because we fell in love with the cute little cub a decade ago. If we lose the memories of our past selves we cannot function as social beings in a full sense and we no longer know who we really are.

But if our memories of the past including our own beliefs, values and commitments, can change depending on the power of a new communicative input, where is the guarantee that promises that people make will be kept, that debts will be paid, and contracts fulfilled? The answer is, there is no such guarantee. When we enter into an obligation we reach out and delve into the future, aiming at manipulating it while standing on the platform of the present situation. All our pledges and promises made at time $t$ which concern the future time $t^{\prime}$ are attempts to jump ahead into the non-existent future and already give it 
some definite shape. We make decisions about the future as it is seen from our present, but whilst standing in our present we can only gain a view of the future that is determined by this particular standpoint. While we are in the present, our imagined future gravitates towards this present, but when it becomes present reality, it will no longer use our present as a reference point. It will be present itself, full of complex embodied eventuality that could not have been fully predicted. The real future is unknown and uncertain, because although we may be able to predict some of its features from our present standpoint, real future will be disengaged from our former projections. Our former present in which promises were made will become the past of the new present that was formerly the future, and will impose its own character on what is going on, at the same time adjusting the past to serve its new reality as a logical and ontological foundation. When the future is still future, it may be pliable and complying with our plans, but when it becomes embodied present, it gains its own powers, bursts out of our plans which, made in the past, have become outdated, and asserts its supremacy of the reality that is happening now and dictating to us what we can and cannot do right now, but also informing us about what we want to do, and that will be determined by current circumstances and not by our previous situations. When we make future plans we do not found them on the future, we found them on the past and the present, so when the future comes, there is always a shift between what we intended to do and how we realise these intentions, and if the shift is significant, we reconsider our past in which the commitment was made, evaluate the former commitment as breakable, and break it.

This happens when people divorce if current circumstances make them re-evaluate their original promise of eternal love, or when students drop out of university courses if the new state of affairs renders their original determination to obtain a degree irrelevant. This is what happened when the Russian people of the early XIX century broke there allegiance to the crown and ruling classes because Marxist ideas demonstrated to them that their allegiance was founded on the principles of exploitation.

Divorces, breaches of contract and revolutions are not the imperfections of social reality that could be in principle avoided as society strives for perfection. These failings are part of the normal running of events, inasmuch as the reconstruction of memories, triggered by a new communicative input, involves memories of our social commitments. In the light of our discussion these breaches and betrayals contribute to the evolvement of communicative reality that develops in its own right and for its own sake, and not for the 
benefit of its participants. ${ }^{22}$ These betrayals are the betrayals of the original past, but that past is no longer that original past, and the decision to disengage form it means an alignment with new reality that includes an alignment with what the original past has become.

For example, let us imagine an eighteen-year-old young man who has made a decision to join the army for the rest of his life. He is motivated by the promise of adventure, the prestige of wearing a uniform, and the significance of the idea that he will be serving his country. Ten years on he may decide to change his career thus breaching the original pledge of a lifelong service. The original eighteen-year-old would disapprove of this pledge being broken, but a mature man cannot be guided in his current actions by promises made by a teenager whom he sees retrospectively as a naïve and inexperienced youth, and so the soldier cannot remain faithful to that original past. At eighteen, he gave himself enough authority to decide on behalf of the future twenty-eight-year-old, but the twenty-eight-year-old has taken this authority away from the youngster retrospectively.

A similar problem would arise if a hostage was to make a promise to her kidnapper that she would protect his identity if he released her. After being released, she may wonder whether she should keep or break that promise. Looking back, she could relieve her previous self of the authority to make a pledge because it was made under the threat of being killed, although the original promise had to be genuinely made for the sake of the hostage's release.

Interestingly, there are ways in which society recognises retrospective changes and adapts to them. According to Article 78 of the Criminal Code of the Russian Federation, people are released from the penal responsibility if their crime was committed a long time ago, from two years for non serious crimes to fifteen years for serious ones, such as murder. ${ }^{23}$

22 It is important to distinguish the success of a communicative process from individuals gaining from that process. A communicative process can be successful in itself but its success may involve someone's unhappiness, as in a sad life story, or physical pain, when sportsmen and women push their physique beyond human limitations whilst causing euphoria for their fans. A beautiful dance can be painful for the dancers. Communicative reality thus can successfully evolve at the expense of its participants' interests.

\footnotetext{
${ }^{23}$ Уголовный кодекс РФ, Статья 78. Освобождение от уголовной ответственности в связи с истечением сроков давности.
} 


\section{Conclusion}

Thus the acceptance of the ontological legitimacy of retrospective changes and memory fabrication complicates not only the problems of perception, judgement and morality. It will also affect the way in which we look at human self and its integrity, emphasising the need to consider temporal orientation as a factor that contributes to our sense of self. There are people who seem to be tuned to change, absorb all the new features of the present and are not attached to the original past which they are ready and eager to reevaluate and reconstruct. We can also think of people who prefer to remain faithful to some original past, resisting the process of memory adjustment.

It will also affect the way in which we see communication. We communicate with people that have different temporal orientation, and the diachrony between interlocutors must be taken into account, just as we take into account people's cultural and social specificity. There are people who flex with every new present, with ease adopting new words and familiarizing themselves with new technology as soon as it appears on the market. Their past is quickly and painlessly altered. They gravitate towards each new movement. There are people who adapt themselves to changes but are one step behind. New stuff comes, but they need a period of time to catch up. They gravitate towards the time that precedes their current present. There are people who gravitate towards a particular period, typically when they were young adults. That period, altered by the following events, is nevertheless favoured and treated as if one has original memories of it.

But those latter people cannot be faithful to their entire original past because one's entire past contains a multitude of phases that were present and became past, with present ones changing past ones all the time. Thus one would have to be faithful to a multitude of original pasts, which would not be adjusted to one 
another and remain in a disjointed state. If one chooses a period that one wants to be faithful to, then every other temporal period will be seen from the standpoint of that time (contaminated by the actual standpoint in real present nonetheless), and the originality of the initial reality will not be allowed to be retrospectively changed. It is impossible to resist such a change however, and what actually happens is that the chosen period in the past is favoured over other, newer, periods, its positive features are inflated and its negative features are toned down. Every other period is seen as a deviation from the favoured period, and if, say, the favoured reality is $1960 \mathrm{~s}$, then we may expect the 60 s fan to prefer vinyl records to CDs, to use a corded telephone set and even give moral justification for using older technology. 